\title{
Continuous improvement in The Netherlands: a survey-based study into current practices
}

\author{
Rick Middel $^{*}$ \\ Department of Operation, Organisation and Human Resources \\ School of Business, Public Administration and Technology \\ University of Twente \\ P.O. Box 217, Enschede, The Netherlands \\ E-mail: h.g.a.middel@bbt.utwente.nl \\ *Corresponding author
}

\section{Saskia op de Weegh}

Faculty of Behavioural Science

University of Twente

P.O. Box 217, Enschede, The Netherlands

E-mail: s.opdeweegh@gw.utwente.nl

\section{José Gieskes}

3 Chemin de la Grand Mare

78240 Chambourcy, France

E-mail: jose.gieskes@chambourcy.nl

\begin{abstract}
Continuous Improvement (CI) is a well-known and consolidated concept in management literature and practice, and is considered vital in today's business environment. In 2003, a survey, which is part of the international CINet survey, was conducted in The Netherlands in order to gain insight into current practices and the evolution of continuous improvement over the past five years. This article describes the results of the Dutch survey, from a sample of 51 companies. The main motives found for continuous improvement were customer satisfaction, productivity, quality, and delivery reliability. CI contributed to several performance areas, but the implementation of CI was fraught with many difficulties. It appears that it is difficult for companies to design and implement an approach towards continuous improvement that is in line with their own perceptions.
\end{abstract}

Keywords: Continuous Improvement (CI); survey; The Netherlands.

Reference to this paper should be made as follows: Middel, R., op de Weegh, S. and Gieskes, J. (xxxx) 'Continuous improvement in The Netherlands: a survey-based study into current practices', Int. J. Technology Management, Vol. X, No. Y, pp.000-000.

Biographical notes: Ir. H.G.A. Rick Middel is a $\mathrm{PhD}$ candidate at the Faculty of Business, Public Administration and Technology at the University of Twente. He studied Industrial Engineering and Management at the University of Twente (NL). From 2002 to 2003, he was a Research Assistant at the 
Department of Technology and Organisation at the University of Twente (NL). His research interests are in continuous improvement, collaborative improvement, action learning and action research.

Ir. Saskia op de Weegh studied Industrial Engineering and Management at the Faculty of Business, Public Administration and Technology at the University of Twente. She finished her Master's Programme in Human Resource Development in 2004 at the Faculty of Behavioural Science. Currently, she works as a Research Assistant on knowledge productivity in organisations with a focus on conditions and interventions that stimulate the learning and knowledge productivity in innovation projects in organisations.

Dr. José F.B. Gieskes worked as a Consultant and Researcher at the School of Business, Public Administration and Technology of the University of Twente for 20 years. During that period, she was involved in a project on developing time standards for professionals, quality management, improvement management and organisational learning. Her $\mathrm{PhD}$ research was on how to stimulate learning behaviour in product innovation processes. After she left the University of Twente, she worked as a manager of a number of outdoor patients' clinics of Medisch Spectrum Twente, a large hospital in Enschede, The Netherlands.

\section{Introduction}

Today, more than ever, companies are challenged to improve their performance and to respond quickly and accurately to changes within the market. Some do this through major (radical) changes and some through small (incremental) changes. Incremental improvement is a well-known concept and widely discussed in the literature on Continuous Improvement (CI). CI is a consolidated concept in managerial theory and practice (Imai, 1986; Robinson, 1991; Bessant and Caffyn, 1997; Boer et al., 2000). Although CI alone is not sufficient, it is recognised as an essential driver of long-term competitive advantage (Boer et al., 2000).

The earliest accounts of CI-related concepts go, at least, as far back as the 18th century. Although these attempts are not based on scientific methods of identifying and analysing improvement possibilities, they have some key ingredients of CI in place (Van der Bij et al., 1999). A key factor in the 'professionalisation' of CI was the introduction of Scientific Management, where CI was defined and described as a key issue (Taylor, 1912). The concept of CI was further developed as a new field in Operations and Innovation Management through descriptions of the Japanese practice of Kaizen. While continuous improvement may not have been invented in Japan (Kerrin, 1999), a rich stream of literature bloomed, describing successful applications of Kaizen in manufacturing processes of Japanese companies (see Imai 1986; 1997). During the 1990s, a new stream of literature on CI emerged, characterised by a much higher emphasis on the role of management, setting the strategic, organisational and cultural conditions for the diffusion of CI to the overall workforce. An important contribution in this direction was delivered by Bessant et al. (1994) and the CINet research network (Caffyn, 1998). Bessant et al. (1994) summarise the organisational factors that are needed to support continuous improvement, with tools and techniques being only two of the 
organisational factors that support CI. Bessant et al. (1994) asserted that organisational learning and knowledge management are key issues in CI. An important strand of research has also been developed to assess the degree of adoption of continuous improvement practices (for example, Coughlan et al., 1997; Gieskes et al., 1997; Chapman et al., 1997; Terziovski and Sohal, 2000; Delbridge and Barton, 2002).

There are various definitions and conceptualisations of continuous improvement, but for the purpose of this article, $\mathrm{CI}$ is best understood with the following definition: "the planned, organised and systematic process of ongoing, incremental and company-wide change of existing practices aimed at improving company performance" (Boer et al., 2000, p.1). Adding to this definition, Boer et al. (2000) give insight into some key aspects and terminology in the current understanding of $\mathrm{CI}$, which are:

- suggestion, recognition and reward and training systems

- methods, tools and techniques

- individual and team-based contributions

- $\mathrm{CI}$ as a normal day-to-day activity

- company-wide involvement and commitment

- strategy-driven and strategy-forming

- empowerment

- facilitating individual and organisational learning

- multiple projects (taking place simultaneously)

- applied in all sorts of organisations.

Within the concept of CI, models, methods and techniques have been developed and more or less successfully implemented in organisations (Boer et al., 2000). The problem with CI is that such an apparently very simple and attractive concept appears to be difficult to design, implement and develop successfully (Bessant, 1998; Boer et al., 2000). "Despite its attraction, evidence suggests that CI often fails, or fails to take root in organisations which try to implement it" (Bessant, 1998).

In a recent literature review, Boer and Gertsen (2003) indicate that the development and validation of theory and the management concepts and tools based on it still deserves a lot of attention within the field of CI. This article gives an insight into the current practices of CI in The Netherlands based on the findings of the CINet survey 2003. As such, it is descriptive in nature, describing the different practices of CI (see also De Lange-Ros, 1999), which can ultimately contribute to, and be used in, the development and validation of CI within firms.

The article is structured as follows. First, we present some general information on the background and general characteristics of the organisations that have participated in the CINet survey in The Netherlands. Next, we discuss the results of the survey in terms of the organisation and operation of CI, support for and tools used in improvement activities, and the effects of improvement activities. In this section, we will present and discuss the most striking results of the survey. Throughout the article, the findings are analysed in order to gain insight into the applicability of some of the theories and models of CI. Finally, in the last section, we draw some conclusions based on the Dutch results of the CINet survey. 


\section{CINet survey}

In 1995, an internationally coordinated study of CI practices and performance in Australia, Denmark, Finland, The Netherlands, Norway, Sweden, and the UK was performed. The study, comprising more than a thousand manufacturing business units, was undertaken by CINet and the Innovation and Continuous Improvement Technologies Research Centre (InCITe) at the University of Western Sydney, Macarthur, Australia (Boer et al., 2000).

The 1995 survey showed that CI was a relatively new phenomenon for the Dutch industry, which had a rapidly growing number of companies looking at this concept with more than average interest. It was found that the implementation of CI was partly driven by market demands, and that costs and delivery reliability were important motivators. Secondly, the survey showed that the tools and techniques that were perceived as valuable frequently received limited use, and those that were used were fairly simple, process-related and problem identification tools (Gieskes et al., 1996; 2000).

The School of Business, Public Administration and Technology of the University of Twente conducted a second CINet survey in 2003 in The Netherlands. The questionnaire was centrally developed by the CINet and translated from English into Dutch. In total, 499 questionnaires were sent out to companies in The Netherlands. Of the questionnaires that were distributed, 51 questionnaires were returned in a workable form, a response rate of $10 \%$. The reason for this low response (compared to the response rate of $40 \%$ in 1995 ) is (partly) explained by the kind of research, the time-consuming questionnaire, and the fact that companies in The Netherlands complain about the number of surveys they receive. There is no evidence that organisations in The Netherlands are less interested in CI.

\section{Background and general characteristics of the organisations}

The companies in the survey represented different branches (ISIC 28-35) and there was a broad coverage of industries in The Netherlands (see Figure 1). The main function indicated by the companies was production. Other functions that were also identified by the companies as important were Logistics/Distribution and R\&D/Product design/Product development.

Figure 1 Sample breakdown according to the type of industry

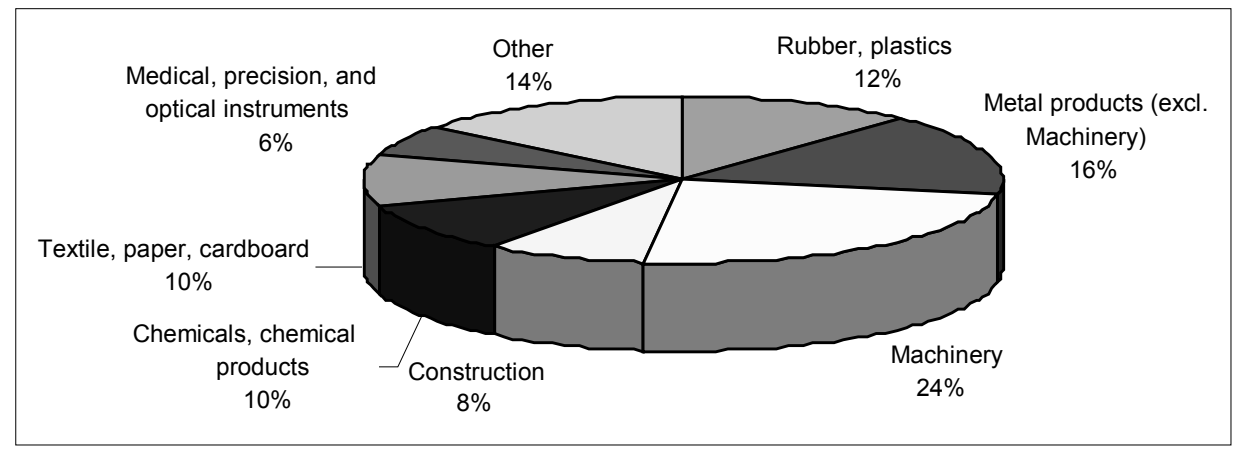


The companies were asked to indicate to what extent the importance of several performance indicators changed over the last three years. As Figure 2 shows, price, product design, time-to-market and delivery reliability are indicators that have increased in importance over the previous three years. Market developments, including intensified international competition and rapidly changing technology developments, are the main challenges for companies nowadays and require them to constantly monitor their cost-structure in order to remain profitable. Price is still regarded by many companies in The Netherlands as an important order/winning criterion. The results of product design/innovation and time-to-market are notable. Despite the fact that the majority of the 51 companies indicate an increase in the importance of both indicators, some companies indicate that product design/innovation and time-to-market became less important. Both answers are remarkable, since innovation is a key issue for companies (see also Tidd et al., 2005) and short time-to-market is seen as essential in today's competitive environment.

Figure 2 Change in importance of indicators over the last three years

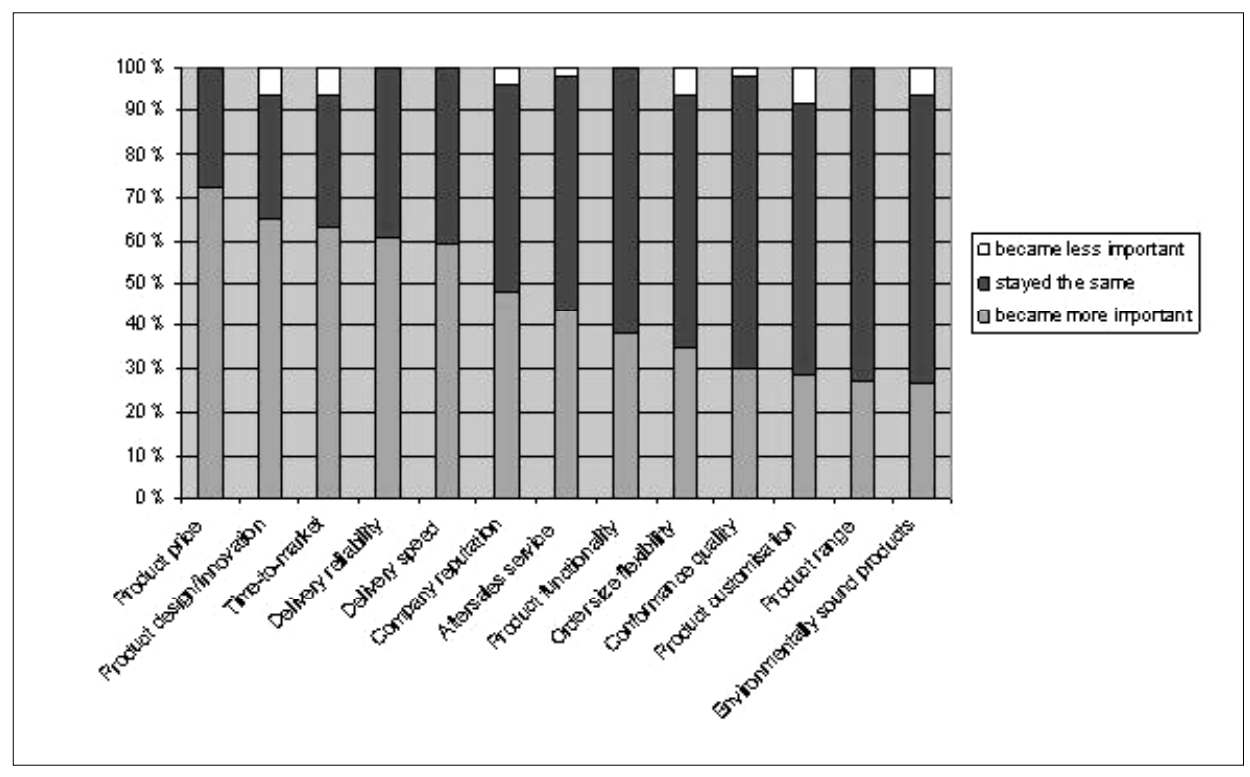

Indicators that became (to some extent) less important are order size flexibility, product customisation and environmentally sound products. The change in the importance of the performance indicator order size flexibility can be explained by the fact that companies increasingly link their internal processes with external customers and suppliers (see also Frohlich and Westbrook, 2001). The (logistic) supply networks allow companies to balance the supply and demand and, consequently, decrease the importance of flexibility in the order size. The decrease in importance of the indicator product customisation can be partly explained by the 'modular age' (see Garud et al., 2003) as companies in The Netherlands increasingly use modular design in the development of products. One of the reasons for the decrease in importance of environmentally sound products in The Netherlands is that the environment is not such a 'hot' item anymore on the agenda of the government and the companies. 


\section{The organisation and operation of CI}

Companies in The Netherlands have, for a long time, been actively engaged in improvement activities. The results of the survey showed two peaks that indicated a lot of companies becoming actively engaged in CI. The first peak, in the early 1990s, can be explained from a historical perspective due to increased interest in The Netherlands in the ideas of Imai (1986) and the founding of the Institute of Dutch Quality in 1991, an initiative of the Ministry of Economic Affairs. The second peak, around the year 2000, can be explained by increased attention of companies in the INK management model ${ }^{1}$ and ISO9001.

$\mathrm{CI}$ is seen as a company-wide change process of existing practices, which requires the involvement and commitment of the entire organisation. The results of the survey indicate that improvement activities within companies in The Netherlands are widely spread throughout the organisation: the departments of quality, NPD, engineering, production and logistics do have frequent improvement activities or improvements that are integrated as part of daily life. As stated earlier, CI is seen by many companies as vital in today's business environment. The high score of the managing director/management team with regard to how widely spread improvement activities are, represents the strategic importance of $\mathrm{CI}$ in today's business environment.

Improvement activities were carried out during regular working time (98\%) and during unpaid overtime (2\%). These activities were carried out in ordinary meetings of cross-functional CI teams (27\%) and in meetings of regular work teams (26\%). To a lesser extent, these activities were carried out in spontaneous meetings (17\%), by individuals (17\%), and in special meetings (13\%). Apparently, CI is regarded as a regular activity.

There are many motives for companies working with $\mathrm{CI}$ in the organisation (see Figure 3). The companies indicated that their main motives are:

- higher customer satisfaction $(85 \%)$

- increased productivity $(82 \%)$

- improved quality conformance (81\%)

- improved delivery reliability (79\%).

Figure 3 illustrates the main indicators of price, product design, time-to-market and delivery reliability. Notably, cost reduction is not seen as one of the main motives for CI, whereas product price is one of the most important indicators. Although higher customer satisfaction is one of the main motives, the departments of marketing \& sales and after sales service, which are in close contact with the customer, only have occasional improvement activities. Motives that are perceived as less important are: CI as a management directive (10\%), improve administrative routines (29\%), and decrease absence (32\%). Based on the results, it can be concluded that CI mainly focuses on changing and improving primary processes and to a lesser extent on administrative and directive processes, a finding in accordance with the CI literature (Gieskes et al., 1996; Boer et al., 2000). 
Figure 3 Main motives for CI

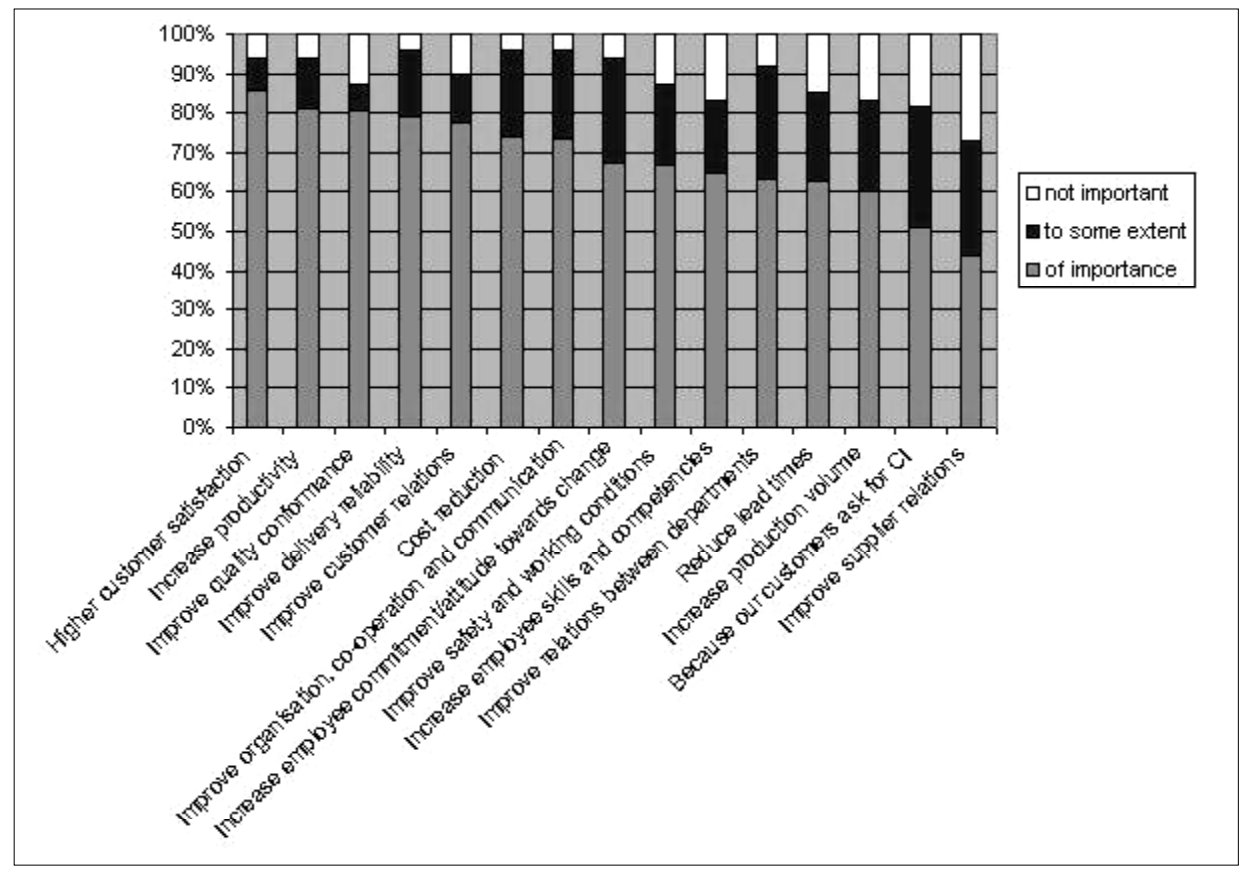

If we compare the results of the 2003 survey with the results of the 1995 survey, a change in the main motives is noticeable (see Table 1).

Table 1 Comparison main motives for CI 1995-2003

\begin{tabular}{ll}
\hline \multicolumn{2}{c}{ Main motives for CI } \\
\hline 1995 & 2003 \\
\hline 1 Cost reduction & 1 Higher customer satisfaction \\
2 Improve employee commitment & 2 Increase productivity \\
3 Improve quality conformance & 3 Improve quality conformance \\
4 Improve organisation, cooperation and communication & 4 Improve delivery reliability \\
\hline
\end{tabular}

It is interesting to observe that at this moment, the main motive is an externally driven motive, whereas in 1995, the cost issue (internally directed) was considered the main driver. Also, the fact that improving employee commitment is no longer in the top three motives raises questions with regard to what drives companies on the issue of improvement. The results of the survey on the topic of performance indicators (see Figure 2) seems to be in line with the main motives for CI.

The general experiences with improvement activities indicate that spreading change efforts to other departments/units (52\%) and raising sufficient resources for CI activities $(48 \%)$ ranged from difficult to very difficult for the companies. Initiating concrete changes $(31 \%)$ and aligning CI activities and overall business strategies are, relatively speaking, easier with an increase in the attention of management. Nevertheless, it appeared that there were frequent problems in the implementation of improvement 
activities. The most frequently encountered problems in implementing improvement activities were: not enough time, not enough knowledge/capabilities/experiences, insufficient performance measures, and lack of goal clarity or ambiguity.

In relation to CI activities, there appears to be a great distinction between individual learning and organisational learning. In the survey, a number of statements with regard to learning were listed. The results showed that individual learning, as part of the improvement activity, were sufficiently present in the organisations, although it had to be stimulated and facilitated by the organisation. Learning does not happen by itself. Stimulation and facilitation were particularly important in terms of spreading change efforts throughout the organisation and learning from each other. Organisational learning appeared to be a 'bridge too far' in terms of the sharing of improvement experiences by individuals and groups. Especially, the institutionalisation of improvement and learning experiences in the organisation and improvement system was lagging behind.

\section{Support for and tools used in improvement activities}

The most important tools, according to the companies in the survey, for establishing incremental improvement are:

- $\quad$ supportive leadership (96\%)

- $\quad$ support from managerial staff $(92 \%)$

- regular shop floor visits by management $(90 \%)$

- monitoring the improvement activities (88\%)

- face-to-face communication (86\%)

- training of personnel in problem-solving tools (82\%)

- general problem-solving format (82\%)

- working in teams/work groups $(78 \%)$.

Tools that are not regarded as important are: promotion through competitions and awards $(6 \%)$, quality awards (16\%), and incentive systems (19\%). The survey made a distinction between how important a company perceives a means for establishing CI and how often they are used. If we compare the values of the importance of a certain improvement tool with the usage of the same improvement tool in the companies, some interesting results appear:

- A group of tools is perceived by the companies as less important and usage is rare. These include promotion through competitions and awards, usage of slogans, incentive systems, a suggestion scheme, usage of Total Productive Maintenance, quality awards (e.g. Baldridge), and formal policy deployment. An important but rarely used tool is training of personnel in problem-solving techniques. 
- A second large group of tools is characterised by high importance and high usage. This group includes monitoring improvement activities, support from managerial staff, supportive leadership, working in teams/work groups, a general problem-solving format (e.g. PDCA), face-to-face communication, and regular shop floor visits by management. In general, it appeared that the usage of tools in establishing incremental improvement was lacking when compared to the perceived importance of the same tools by the companies. However, there was one exception. 'ISO9000/2000, or any other quality standard' was very frequently used in establishing CI compared to the importance of the tool.

As Table 2 shows, the incentives that were perceived as less important in companies were used rarely. Despite the notion of the importance of incentives in establishing CI, both in practice and theory, incentives were not a structural part of the design and implementation of CI in The Netherlands.

Table 2 Importance/usage of incentives in establishing CI

\begin{tabular}{lcc}
\hline & $\begin{array}{c}\text { Importance (percentage } \\
\text { response 'important') (\%) }\end{array}$ & $\begin{array}{c}\text { Usage (percentage } \\
\text { response 'rarely') (\%) }\end{array}$ \\
\hline $\begin{array}{l}\text { Suggestions are evaluated and rewarded } \\
\begin{array}{l}\text { Improvement results are rewarded directly } \\
\text { through one-off bonuses }\end{array}\end{array}$ & 43 & 70 \\
$\begin{array}{l}\text { Improvement results are rewarded } \\
\text { indirectly through individual salaries }\end{array}$ & 24 & 86 \\
$\begin{array}{l}\text { Improvement results are not rewarded } \\
\text { monetarily, but through development of } \\
\text { individual job, careers, etc. }\end{array}$ & 47 & 71 \\
$\begin{array}{l}\text { Improvement results are rewarded to } \\
\text { entire teams }\end{array}$ & 59 & 49 \\
\hline
\end{tabular}

A supporting incentive system for $\mathrm{CI}$ is one of the key items of $\mathrm{CI}$, according to literature. Despite this notion of importance, it can be concluded that companies within The Netherlands have not implemented such a supporting incentive system on a structural basis.

The companies were asked to indicate which problem-finding and -solving tools were used in improvement activities and how important they perceived the tool. The most important problem-finding and -solving tools were:

- $\quad$ problem identification tools/checklists (70\%)

- $\quad$ process mapping tools $(68 \%)$

- $\quad$ display/visualisation tools $(60 \%)$

- $\quad$ seven basic quality tools $(56 \%)$.

Less important tools were simulation (19\%), Six Sigma (23\%), and QFD (26\%). 
The four most important tools, mentioned above, were used most frequently. The tools that were used rarely are also perceived as less important tools in establishing CI. The exceptions were the creativity tools/idea generation tools, FMEA, and seven 'new' quality tools, which were perceived as important; but the companies' usage of these tools compared to the other tools was lower in The Netherlands.

\section{The effects of improvement activities}

Companies in The Netherlands rated the overall importance of continuous improvement as vital for their business $(26 \%)$. Some $47 \%$ of the companies rated the overall importance of CI as strategically important and $27 \%$ as operationally important.

As Figure 4 indicates, over the last three years, CI contributed to the highest extent to areas of improved quality conformance, improved customer relations and improved delivery reliability. A comparison between Figures 3 and 4 shows some similarities. Higher customer satisfaction, improved delivery reliability and improved quality conformance were important motives for working with CI, and, apparently, CI contributed to these performance areas.

Figure 4 Contribution of CI to performance areas

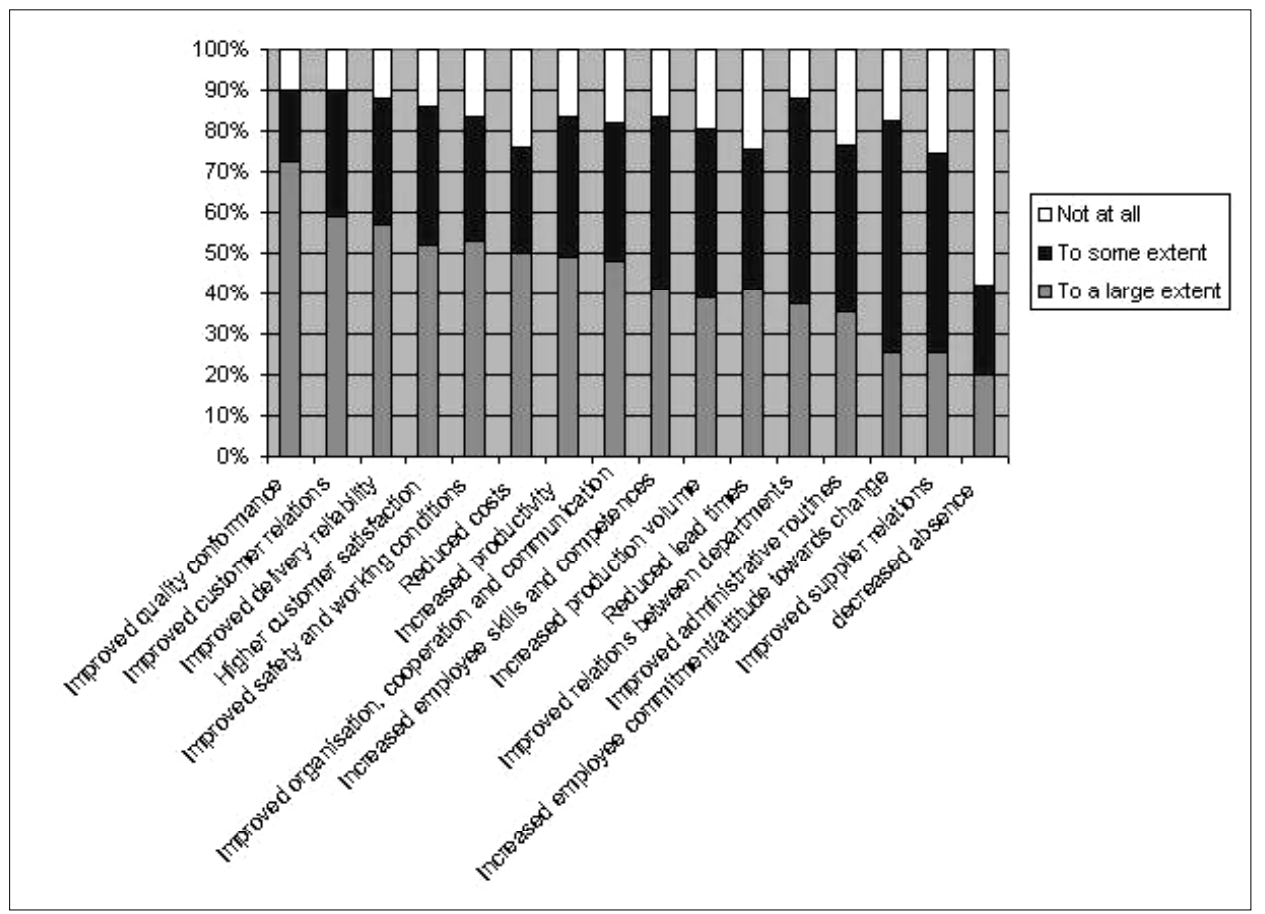

Performance areas to which CI hardly contributed over the last three years were decreased absence and improved supplier relations. These areas were not depicted in Figure 4 as main motives for working with CI. 


\section{Conclusions and future research}

The survey presents a picture of current practices with CI in The Netherlands. The data shows that although the implementation of CI seems to be relatively simple, it appears to be difficult to design, implement and develop successfully. Customer satisfaction, productivity, quality conformance and delivery reliability are important motivators to start working with CI. However, implementing CI can be fraught with difficulties - with lack of time, lack of knowledge/capabilities/experiences, ambiguity, and insufficient performance measures - being the most frequent. These four problem areas correspond with the disablers of learning in product innovation identified by Gieskes (2001). Apparently, the four problem areas can be characterised as being necessary conditions for a successful implementation of CI.

The key to CI is development and learning (Boer et al., 2000). The survey indicates that individual learning is sufficiently part of improvement activities, although it has to be stimulated and facilitated; but organisational learning is presently a 'bridge too far', especially in terms of sharing, diffusing and institutionalising improvement and learning experiences. Facilitation and stimulation by companies of individual learning and, especially, organisational learning is necessary and even required to ensure successful CI.

It appears to be difficult for companies to design and implement an approach towards CI that is in line with their own perception of what is important and what is not. Often, the means and tools for establishing CI that are perceived important have limited use. The same conclusion can be drawn with regard to incentives for CI. Although literature on CI indicates that a supporting reward and incentive system is a key aspect of CI (Boer et al., 2000), there is still a limited use of incentives in actual practice.

The data indicate that CI has become more important on a strategic level. However, ambiguity and the lack of performance measures are frequent problems, which are encountered in the implementation of CI. This suggests that companies should develop a clearer and more consistent top-down approach towards CI.

Definitions with regard to continuous improvement often imply that $\mathrm{CI}$ is an integral part of the daily work practices. Dutch companies do indeed seem to perceive CI as an integral part of their business. However, this survey showed that this perception might be a bit flawed, due to lack of resources, organisation learning as a 'bridge too far', goal ambiguity and insufficient performance measures, and discrepancy between importance and usage in terms of incentives, means and tools.

In the literature, several key aspects of CI are mentioned (Boer et al., 2000; Rijnders, 2002). Although these aspects have been indicated as key in the literature on CI, the findings of this survey show that these aspects also cause most of the difficulties in the design, implementation and development of successful CI.

Within this research, the contingent situations of the companies, e.g. the adoption of quality standards, which is becoming more and more a 'must' in many industries, were not taken into account. Although the authors do recognise the added value of an analysis on the different motivations or different adopted means according to the specific industry or the specific product family, the sample size of 51 companies is too small to draw any conclusions on contingent situations. 
Although this article has presented and described the practice of CI in The Netherlands, there remain four pointers for future research, areas that need to be addressed:

1 The contingent situations of the companies might explain different motivations or different adopted means and tools in CI. As such, more research is required into the relationship between CI practices and industry-specific characteristics or even national characteristics, not only within The Netherlands but also in the CINet community.

2 The CINet 2003 survey has been, to some extent, a replication of the original survey. Further analysis of the findings and comparison between both surveys is required to gain insight into, and develop an understanding of, the evolution of CI practices in The Netherlands over the past years.

3 A central idea to the activities of the CINet community is learning from previous and collaborative work. As such, analysing and sharing the findings of all the CINet surveys of the participating countries are required in order to develop and test theories and models on CI.

4 Constant assessments of CI practices and trends are needed in order to contribute to the evolving concept of CI. Based on these assessments in the field of CI, existing theories will be challenged, tested and added to, and implications and recommendation for managerial practice can be further formulated.

\section{References}

Bessant, J. (1998) 'Developing continuous improvement capability', International Journal of Innovation Management, Vol. 2, pp.409-429.

Bessant, J. and Caffyn, S. (1997) 'High-involvement innovation through continuous improvement', International Journal of Technology Management, Vol. 14, No. 1, pp.7-28.

Bessant, S., Caffyn, S. and Gilbert, Y. (1994) 'Rediscovering continuous improvement', Technovation, Vol. 14, No. 1, pp.17-29.

Boer, H. and Gertsen, F. (2003) 'From continuous improvement to continuous innovation, a (retro)(per)spective', International Journal of Technology Management, Vol. 26, No. 8, pp.805-827.

Boer, H., Berger, A., Chapman, R. and Gertsen, F. (Eds.) (2000) 'CI changes: from suggestion box to organisational learning', Continuous Improvement in Europe and Australia, Aldershot: Ashgate Publishing Ltd.

Caffyn, S. (1998) EuroCINet - The First Three Years: A Report of the Activities and Achievements of the European Network for Continuous Improvement 1994-1997, CINet Publication.

Chapman, R., Hyland, P., Jenkins, R. and Sloan, T. (1997) 'Continuous improvement in Australian manufacturing: findings of a survey in New South Wales', International Journal of Technology Management, Vol. 14, No. 1, pp.102-115.

Coughlan, P., Keating, M. and Bergin, M. (1997) 'Towards an understanding of continuous improvement in manufacturing industries in Ireland', International Journal of Technology Management, Vol. 14, No. 1, pp.139-145.

De Lange-Ros, D.J. (1999) 'Continuous improvement in teams, the (mis)fit between improvement and operational activities of improvement teams', PhD Thesis, Enschede: Print Partner Ipskamp. 
Delbridge, R. and Barton, H. (2002) 'Organizing for continuous improvement, structures and roles in automotive components plants', International Journal of Operations and Production Management, Vol. 22, No. 6, pp.680-692.

Frohlich, M.T. and Westbrook, R. (2001) 'Arcs of integration: an international study of supply chain strategies', Journal of Operations Management, Vol. 19, pp.185-200.

Garud, R., Kumaraswamy, A. and Langlois, R.N. (2003) Managing in the Modular Age, Architectures, Networks, and Organizations, Malden: Blackwell Publishers Ltd.

Gieskes, J., Baudet, F., Schuring, R. and Boer, H. (1997) 'Continuous improvement in The Netherlands: current practices and experiences in Dutch manufacturing industry', International Journal of Technology Management, Vol. 14, No. 1, pp.50-60.

Gieskes, J.F.B. (2001) 'Learning in product innovation processes: managerial action on improving learning behaviour', PhD Thesis, Universiteit Twente, Enschede.

Gieskes, J.F.B., Baudet, F.C.M., Boer, H. and Schuring, R.W. (1996) Continu verbeteren in Nederland: resultaten van een schriftelijke enquête naar stand van zaken anno 1995 met betrekking tot Continu Verbeteren in het bedrijfsleven in Nederland, Twente Quality Center, Universiteit Twente.

Gieskes, J.F.B., Baudet, F.C.M., Boer, H. and Schuring, R.W. (2000) 'Continuous improvement in The Netherlands', in H. Boer, A. Berger, R. Chapman and F. Gertsen (Eds.) CI Changes: From Suggestion Box to Organisational Learning, Continuous Improvement in Europe and Australia, Aldershot: Ashgate Publishing Ltd., pp.89-109.

Imai, M. (1986) Kaizen. The Key to Japan's Competitive Success, New York: McGraw-Hill Publishing Company.

Imai, M. (1997) Gemba Kaizen: A Common Sense, Low Cost Approach to Management, NY: McGraw Hill.

Kerrin, M. (1999) 'Continuous improvement capability: assessment within one case study organisation', International Journal of Operations and Production Management, Vol. 19, No. 11, pp.1154-1167.

Rijnders, S. (2002) 'Four routes to continuous improvement, an empirical typology of CI implementation processes', PhD Thesis, Enschede: Twente University Press.

Robinson, A. (1991) Continuous Improvement in Operations, A Systemic Approach to Waste Reduction, Cambridge, MA: Productivity Press.

Taylor, F.W. (1912) Scientific Management, Dartmouth College, Hanover, NH.

Terziovski, M. and Sohal, A. (2000) 'The adoption of continuous improvement and innovation strategies in Australian manufacturing firms', Technovation, Vol. 20, pp.539-550.

Tidd, J., Bessant, J. and Pavitt, K. (2005) Managing Innovation, Integrating Technological, Market and Organizational Change, Chicester: John Wiley \& Sons Ltd.

Van der Bij, J.D., Broekhuis, M. and Gieskes, J.F.B. (1999) Kwaliteitsmanagement in Beweging, Deventer: Kluwer.

\section{Note}

1 Source: www.ink.nl 